\title{
A note on the Gadi Central Pandam Sacred Grove of East Sikkim, Sikkim, India.
}

\section{Sankara Rao M.1*, Ashok Kumar Panigrahi², Alaka sahu ${ }^{3}$}

${ }^{1}$ Botanical Survey of India, Sikkim Himalayan Regional center, Gangtok, Sikkim-737 103, India.

(Redeployed at BSI, DRC, Hyderabda-500048).

2Department of Botany, Division of Environmental Science, Berhampur University, Berhampur, Odisha, India.

${ }^{3}$ Department of Botany, R.N. College, Dura, Berhampur, Odisha-760 010, India.

Received: 7/4/2017; Accepted: 7/21/2017

\begin{abstract}
Sacred groves are small forest patches conserved by local people through socio-religious and historical beliefs. Gadi Central Pandam is one of the oldest sacred groves and protected more than 300 years due to its various religious, historical and archaeological significances. It is situated in the Sumin Resrve Forest of Rangpo Block of East Sikkim District. The sacred grove harbors a wide variety of plant species. This grove is facing serious threats due to various developmental activities. Therefore, it is suggested here to create awareness among the native people about the traditional values of this sacred grove and environmental benefits to the region and better sustenance of mankind by conserving the biodiversity of the region. The native people should also be encouraged to involve actively in protection and sustainable conservation managements of this grove for posterity.
\end{abstract}

Keywords: Biodiversity, Sacred Grove, East Sikkim, Conservation.

\section{Introduction}

India has tremendous history towards conservation of plants in a particular locality due to some socioreligious and historical beliefs. That practice continues even today in all most all areas, through offering pujas of particular plants and veneration of forests, presently those areas popularly called sacred groves. Gadgil and Vartak did extensive studies during mid-1970s. In India, so far about 13,720 sacred groves have been enumerated, and the total number of sacred groves in the country expected to be more than 1.5 lakh (Malhotra et al. 2001). They are rich in rare and endemic species of plants and represent a tradition of conservation, management and even sustainable development of natural resources (Ramakrishnan et al., 1998). In the North-Eastern regions, sacred groves are found in Assam, Meghalaya, Arunachal Pradesh, Manipur and Sikkim (Dash et al., 2002). In Sikkim, the sacred groves those attached to local monasteries are popularly known as "Gumpas". The sacred groves are dedicated to local deity and are managed by Gumpa authorities, or by the village communities.

Gadi Central Pandam Sacred Grove is located in Sumin Reserve Forest of Rangpo block of Singatam territorial range of East Sikkim district. It spreads over an area of more than 5 acres, and lies between $27^{\circ}$ $13^{\prime} 14.2^{\prime \prime} \mathrm{N}$ and $88^{\circ} 31^{\prime} 59.6^{\prime \prime} \mathrm{E}$, at elevations range from 1700 to $1890 \mathrm{~m}$ (State Forest Department Report, 2011). The forest of sacred grove belongs to tropical to temperate forestand shows wide variety of plant diversity.
While conducting field surveys during 2016, we have collected data from locals by using data sheet and interestingly found that, this grove is more than 300 years, presently, protected by single individual family and conserved by local community and Joint Forest Management (JFM) members due to some socioreligious-historical beliefs and archeological significance. Generally, every Tuesdays and Fridays, devotees from different locality visit this sacred grove and offer pujas to the popular deity 'Gadi Matha' and the other deity 'Shiva'. Some of the devotees offer prayers in traditional Buddhism style.

All communities of the village jointly organize religious rituals twice in a year during October (Durga puja) and April (Sri Ramnavami). The devotees usually do offerings and pujas to the deity for security/protection of their village from evil spirits, and also for good heath, good environment and climate support for good harvesting of crops. During the present study, it has been observed that due to various developmental activities this grove is facing serious threats. Therefore, it is necessary to create awareness among the local communities about the importance of this sacred grove in conserving the biodiversity and traditional ethic values for posterity. As for a proper conservation plan and effective management of this sacred grove it is important to document the plant diversity of the grove.

\footnotetext{
*Corresponding Author:

Dr. Sankararao Mudadla,

Botanical Survey of India,

Sikkim Himalayan Regional Centre,

Gangtok-737103, India.

(Redeployed at BSI, DRC, Hyderabda-500048)

E-mail: mudadlas@gmail.com 


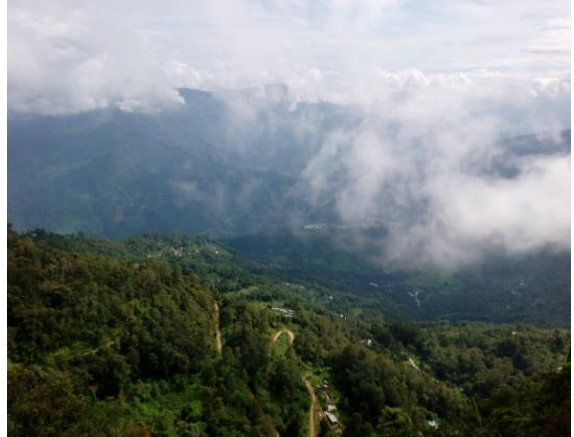

Vegetation view

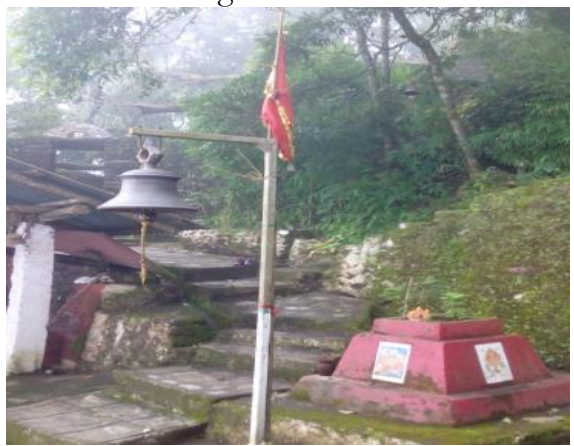

Sacred way at Gadi

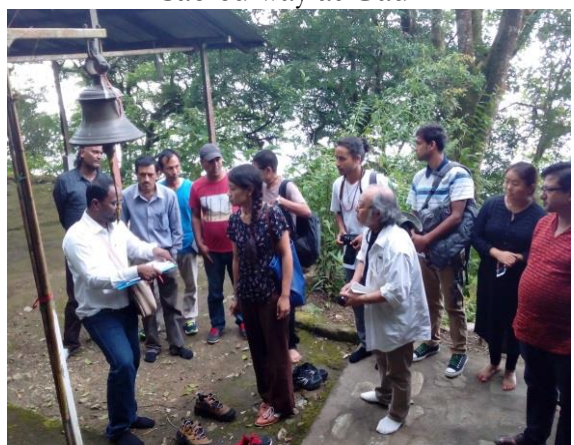

Interaction with Japan International Cooperation Agency (JICA) members

\section{Acknowledgements}

The authors are thankful to Dr. Paramjit Singh, Director, Botanical Survey of India (BSI), and Dr. D.K. Agrawala, Scientist In-Charge, BSI, Sikkim Himalayan Regional Centre (SHRC), Gangtok, for providing facilities. They are grateful to the Forest Department officials, Government of Sikkim, for granting permission and local people and Joint Forest Management (JFM) members for their support during field surveys. The authors also thank Dr. J. Swamy, S. Nagaraju BSI, DRC, Hyderabad, Dr. David L. Biate, Scientist, Mr. S.K. Rai, and Mr. Subash Pradhan BSI, SHRC, Gangtok, for valuable co-operation during the study.

\section{References}

1. Dash, S. S. and Chauhan, A. S. Kabi sacred grove in Sikkim. Relevance to conservation. Prospectives of Biodiversity (ed. Dash, A. P.), Bishen Singh Mahendra Pal Singh, Dehra Dun, 2002, pp. 713731.

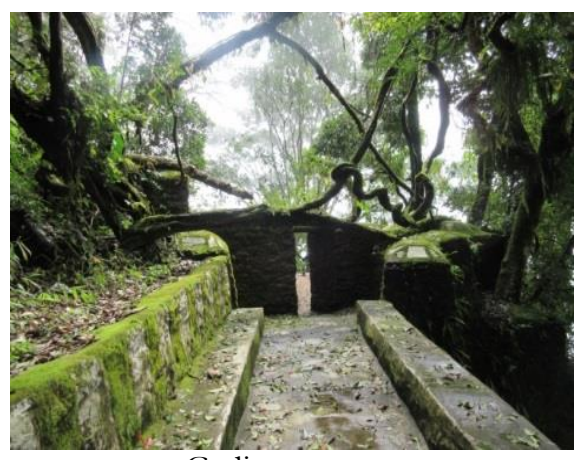

Gadi entry area

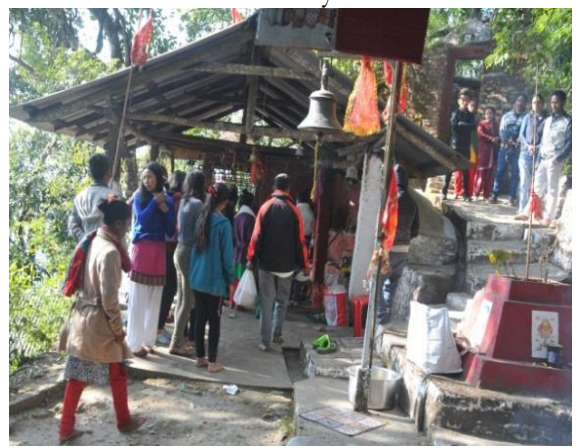

Devotees at Gadi

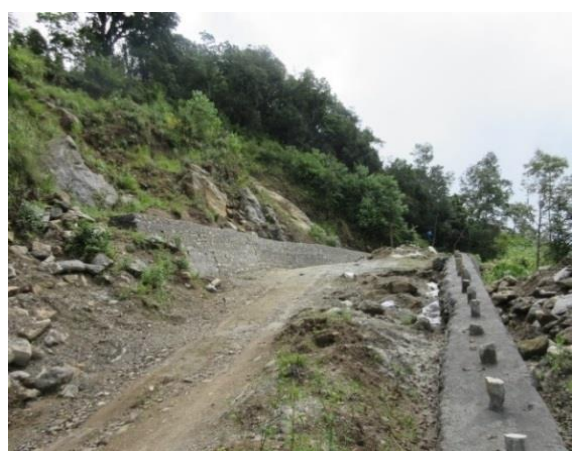

Developmental activity:expansions of roads

2. Forest, Environment \& Wild life management department, Govt. of Sikkim 2011. Sacred Groves of Sikkim. pp.1-26.

3. Malhotra, K. C., Gokhale, Y., Chatterjee, S. and Srivastava, S. Culture and Ecological Dimensions of Sacred Groves in India, INSA, New Delhi, 2001.

4. Ramakrishnan, P. S., Saxena, K. G. and Chandrashekara, U. M. (eds), Conserving the Sacred for Biodiversity Management, Oxford and IBH, New Delhi, 1998.

\section{Cite this article as:}

Sankara Rao M., Ashok Kumar Panigrahi, Alaka sahu. A note on the Gadi Central Pandam Sacred Grove of East Sikkim, Sikkim, India. Annals of Plant Sciences 6.8 (2017) pp. 1656-1657.

doi: http://dx.doi.org/10.21746/aps.2017.08.001 